\title{
Investigation of Regenerated Cellulose/Poly(acrylic acid) Composite Films for Potential Wound Healing Applications: A Preliminary Study
}

\author{
Manjula Bajpai, S. K. Bajpai, and Dinesh Gautam \\ Polymer Research Laboratory, Department of Chemistry, Government Model Science College, Jabalpur 482001, India \\ Correspondence should be addressed to Manjula Bajpai; mnlbpi@rediffmail.com
}

Received 20 January 2014; Revised 14 March 2014; Accepted 17 March 2014; Published 6 May 2014

Academic Editor: Alejandro Rodriguez

Copyright (c) 2014 Manjula Bajpai et al. This is an open access article distributed under the Creative Commons Attribution License, which permits unrestricted use, distribution, and reproduction in any medium, provided the original work is properly cited.

Regenerated cellulose/poly(acrylic acid) composite films have been synthesized for wound dressing applications. The water absorbency of these films was studied as a function of amount of cross-linker $\mathrm{N}, \mathrm{N}^{\prime}$-methylenebisacrylamide and cellulose contents in the feed mixture. The samples, having different compositions, showed tensile strength and percent elongation in the range of $9.98 \times 10^{5}$ to $13.40 \times 10^{5} \mathrm{~N} / \mathrm{m}^{2}$ and 110 to 265 , respectively. The water vapor transmission rate (WVTR) for various films was found to be in the range of 2.03 to $7.18 \mathrm{mg} / \mathrm{cm}^{2} / \mathrm{h}$. These films were loaded with antibacterial drug miconazole nitrate and their release was studied in the physiological $\mathrm{pH}$ at $37^{\circ} \mathrm{C}$. The release data was found to fit well the diffusion controlled Higuchi model. Finally the films demonstrated fair antibacterial and antifungal action, thus establishing their strong candidature as wound dressing materials.

\section{Introduction}

Wound dressing films are three-dimensional cross-linked polymers, which are permeable to gases and moisture and are used to prevent the microbial contamination in wounds [1]. In the past, materials such as honey pastes, plant fibers, and animal fats were frequently employed as wound dressing materials [2]. A potential wound dressing film should have properties such as moisture and gas permeation capacity, mechanical strength, folding endurance (FE), capacity to release the loaded bioactive material, and antimicrobial efficacy. Ultimately, the major function of the wound dressing film is to provide the highest rate of healing and the best aesthetic repair of the wound $[3,4]$. A wound dressing film is desirable to have the following prompt functions: (a) to provide moist environment, (b) to protect wound from microbial infection, and (c) to ease application and removal, avoiding dressing-related trauma $[5,6]$. Wound dressings, loaded with antibacterial agent or drug, are often used to treat wound locally such as anti-infections due to secondary infection or for pain control, especially in chronic wounds $[7,8]$.
Recently, due emphasis has been given to various microbial polysaccharides towards the development of wound dressing materials [9], because of their biocompatible nature, biodegradability, fair water absorbing capacity, and transparency [10]. Some of these polysaccharides include hyaluronic acid, cellulose, alginate, chitosan, and kappa carrageenan $[11,12]$.

Cellulose, a natural polysaccharide and found in abundance, belongs to the most promising class of biopolymers [13]. The unique physical and mechanical properties of cellulose as well as its purity and uniformity determine applications that range from high quality audio membranes [14] and electronic paper [15] to fuel cells [16] and medical materials [17-19]. In recent past, sincere efforts have been made to develop cellulose as a new skin substituent and wound dressing material $[20,21]$, due to its hydrophilicity, fair water retention capacity, high permeability, optimal gelatinization, and high mechanical strength [22].

Hydrogels are three-dimensional polymer networks, and they possess tendency to retain water, which may be helpful in providing moist environment to the wound. Their transparent look can be useful in monitoring the healing 


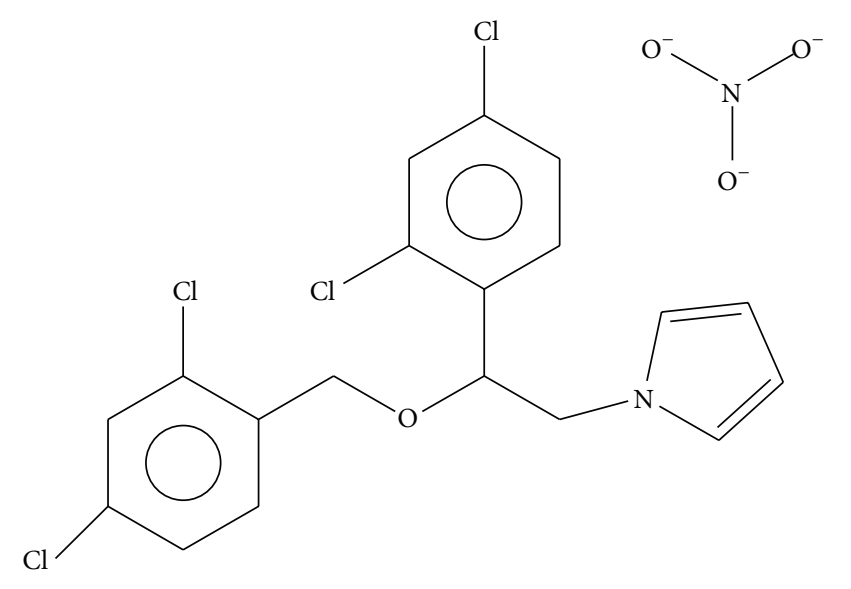

Miconazole nitrate

FIGURE 1: Molecular structure of drug miconazole nitrate.

process visually [23]. In addition, variation in the degree of crosslinking of polymeric hydrogel may be helpful in controlling its mechanical properties, moisture permeability, and release rate of loaded bioactive ingredient [24]. Therefore, combination of cellulose and synthetic polymeric hydrogel could result in an efficient wound dressing film with most of the desirable properties.

Recently, coinage metal nanoparticles such as silver have been used as antibacterial agents in fabrication of wound dressing films [25]. But as per some reports, silver nanoparticles are harmful for human osteoarthritic chondrocytes when used in higher concentrations of around 160-250 $\mu \mathrm{M}$ [26]. Moreover, nanoparticles present in blood are associated with thrombosis and activation of immunological reactions [2729]. As an alternative to metal nanoparticles we here report drug miconazole nitrate loaded cellulose/poly(acrylic acid) hydrogel films for antibacterial applications.

\section{Experimental}

2.1. Materials. Cellulose (Cell) powder was purchased from Central Drug House, Mumbai, India. Its viscosity average molecular weight $(\mathrm{Mn})$ was calculated according to equation $[(\mathrm{y})]=3.85 \times 10^{-2} \mathrm{Mn}^{0.76}$ [25] and was found to be $18.6 \times 10^{4}$. The monomer acrylic acid (AAc), cross-linker $\mathrm{N}, \mathrm{N}^{\prime}$-methylenebisacrylamide (MB), and initiator potassium per sulfate (KPS) were obtained from Hi Media, Mumbai, India. The antibiotic drug miconazole nitrate was obtained from Ranbaxy pharmacy as commercial product Micogel (Figure 1 shows structure of drug miconazole nitrate used in the study). Nutrient broth, nutrient agar, and agar-agar type- 1 were obtained from Hi Media Chemicals, Mumbai, India. The department of biotechnology (Government Model Science College, Jabalpur (Madhya Pradesh), India) provided standard culture of the organisms. Double distilled water was used throughout the investigation.

2.2. Dissolution of Cellulose in $\mathrm{NaOH} /$ Urea Solvent System. Cellulose solution was prepared in $\mathrm{NaOH} /$ urea solvent system according to procedure reported by Jin et al. [30]. In brief, $6 \mathrm{~g}$ of $\mathrm{NaOH}$ and $4 \mathrm{~g}$ of urea were dissolved in $90 \mathrm{~mL}$ of distilled water, and the resulting solution was filtered with a G2 sand filter. Now, $4 \mathrm{~g}$ of cellulose powder was dispersed into $100 \mathrm{~g}$ of above solution under constant stirring for $20 \mathrm{~min}$ and then stored in refrigerator $\left(-5\right.$ to $\left.-10^{\circ} \mathrm{C}\right)$ for $12 \mathrm{~h}$. The frozen solid was thawed and stirred extensively at room temperature to obtain a colorless and almost transparent solution. The cellulose solution was dialyzed against distilled water using a dialysis membrane with 10000 molecular weight cut-off. The dialysis was carried out for a period of 2 days. The resulting suspension was used to prepare the hydrogels as described in the next section.

2.3. Synthesis of Regenerated Cellulose/Poly(AAc) Hydrogel Film. The regenerated cellulose/poly(acrylic acid) (RC/ poly(AAc)) hydrogel film was prepared by free-radical polymerization of AAc in the presence of above dissolved cellulose. In brief, $12.66 \mathrm{mM}$ of monomer AAc, $0.194 \mathrm{mM}$ of crosslinker $\mathrm{MB}$, and $0.295 \mathrm{mM}$ of initiator KPS were mixed into $2.5 \mathrm{~mL}$ of above dialyzed cellulose solution ( $4 \mathrm{wt} \%$ ), and the total volume was made up to $5 \mathrm{~mL}$ by addition of water. The reaction solution was transferred into Petri plates and kept in electric oven (Tempstar, India) at $60^{\circ} \mathrm{C}$ for a period of $2 \mathrm{~h}$. The resulting hydrogel film was peeled off and transferred into $200 \mathrm{~mL}$ of ammonium sulfate solution $(8 \% \mathrm{w} / \mathrm{v})$ for a period of $8 \mathrm{~h}$. Finally, RC/poly(AAc) hydrogel film was taken out and allowed to equilibrate in excess of refreshing water for a period of 7 days till all the remaining chemicals in the hydrogel film were leached out. The compositions of various hydrogel films prepared are given in Table 1.

2.4. Yield of Hydrogel Film. Freshly prepared RC/poly(AAc) hydrogel film was placed in refreshing distilled water till the external medium acquired $\mathrm{pH}$ almost that of distilled water. Now, the swollen hydrogel was placed in 50 percent $(\mathrm{v} / \mathrm{v})$ aqueous solution of methanol for a period of two days. In order to ensure the complete extraction, the gel was transferred into acetone for 12 hours, followed by complete drying.

The percent hydrogel yield was calculated as per the following expression:

$$
\text { Hydrogel yield }=\frac{\text { Dry weight of polymer }}{\text { Total weight of reactants }} \times 100 \text {. }
$$

Here, total weight of reactants includes monomer AAc, polymer cellulose, and cross-linker MB.

2.5. Preparation of Drug-Loaded Film. The drug-loaded films were prepared by adding precalculated amount of drug to the reaction mixture before the polymerization started. This method enables us to incorporate a desired quantity of drug in the polymer matrix. The hydrogel film samples were denoted as $\operatorname{HG}(\mathrm{X})$, where the number in the parenthesis denotes the amount of drug present in one gram of film.

2.6. Water Absorption Study. In the gravimetric method, the preweighed sample was placed in $500 \mathrm{~mL}$ of distilled water 
TABLE 1: Compositions of various hydrogel films synthesized ${ }^{\mathrm{a}}$.

\begin{tabular}{lccccc}
\hline Hydrogel film code & Cellulose $(\mathrm{mg})$ & AAc (millimolar) & MB (micromolar) & KPS (millimolar) & Glycerol (mL) \\
\hline HG1 & 100 & 12.66 & 194 & 0.295 & 0.295 \\
HG2 & 100 & 12.66 & 324 & 0.295 & - \\
HG3 & 60 & 12.66 & 324 & 0.295 & - \\
HG4 & 60 & 12.66 & 194 & 0.295 & - \\
HG5 & 20 & 12.66 & 194 & 0.295 & 0.5 \\
HG6 & 100 & 12.66 & 194 & 0.295 & 1.0 \\
HG7 & 100 & 12.66 & 194 & & - \\
\hline
\end{tabular}

${ }^{\mathrm{a}}$ Total volume of polymerization mixture was $5.0 \mathrm{~mL}$.

at $37^{\circ} \mathrm{C}$, and it was taken out at different time intervals, wiped superficially with tissue paper to remove extra surface water, weighed accurately on an electronic balance (Denber, Germany), and then placed back in water. The swelling ratio SR, obtained at different time intervals, was determined using the following expression [31]:

$$
\mathrm{SR}=\frac{\left(M_{t}-M_{0}\right)}{M_{0}} \times 100,
$$

where $M_{0}$ and $M_{t}$ are the initial mass and mass at different time intervals, respectively.

2.7. Test for Mechanical Properties. The mechanical properties of the films were determined according to the procedure reported elsewhere [32]. Film samples, with the dimensions $39 \mathrm{~mm} \times 5.8 \mathrm{~mm}$, were equilibrated under the $\mathrm{RH}$ of $50 \%$ at $23^{\circ} \mathrm{C}$ for a period of $24 \mathrm{~h}$ and their tensile strength (TS) and percent elongation at break $(E)$ were measured by using an Instron Universal Testing Instrument (Model 1011). The initial grip separation and crosshead speed were set to 40 and $200 \mathrm{~mm}$ per min, respectively. All the determinations were made in triplicate. TS was calculated by dividing the maximum load $(F, \mathrm{~N})$ on the film before failure by the initial cross-sectional area $\left(S, \mathrm{~m}^{2}\right)$, that is, $\mathrm{TS}=F / S$.

2.8. Moisture Permeation Study. As per ASTM E 96-93 method, film sample was placed in between the cup and the silicon coated ring and held tightly using screws provided. A preweighed quantity of silica gel was placed inside the cup to produce $\mathrm{RH}$ of zero percent. The distance between the film and silica gel was about $1.5 \mathrm{~cm}$. The cup was now placed at $25^{\circ} \mathrm{C}$ in thermostated desiccators which contained saturated salt solution to produce $40 \% \mathrm{RH}$. The cup was taken out of desiccators at definite time intervals, and mass was measured using an electronic balance (Denber, Germany). The water transmission rate (WVTR) was calculated [33] as

$$
\mathrm{WVTR}=\frac{\Delta W}{\Delta t \cdot A} \mathrm{mgh}^{-1} \mathrm{~cm}^{-2}
$$

where $\Delta W / \Delta t$ is the amount of water gain per unit time of moisture transfer and $A=$ area exposed to water surface in $\mathrm{cm}^{2}$.
2.9. Drug Release Study. The preweighed drug-loaded film was placed in $25 \mathrm{~mL}$ of release medium (i.e., physiological fluid) at $37^{\circ} \mathrm{C}$. After definite time intervals, film was transferred into fresh release medium, and the amount of drug released was determined spectrophotometrically at $200 \mathrm{~nm}$. The quantity of drug was calculated using Lambert-Beer's law obtained for drug solutions of known concentrations.

2.10. Antimicrobial Experimentations. To test the biocidal activity of drug-loaded Cell/poly(AAc) film in quantitative manner [34], appropriate number of colony-forming units (CFU) of microbes $\left(5 \times 10^{9} \mathrm{CFU} / \mathrm{mL}\right.$ of $E$. coli) were cultured on a nutrient agar plate supplemented with drug-loaded circular film (diameter $5 \mathrm{~mm}$ ) placed at the center of the plates. The plates were examined for a possible clear zone around the fibers after incubation at $37^{\circ} \mathrm{C}$ for a period of $24 \mathrm{~h}$. The plate, supplemented with plain film, was used as control set.

\section{Results and Discussion}

3.1. Percent Hydrogel Yield (PHY). The total weight of cellulose, monomer acrylic acid, and cross-linker (MB) in the feed mixture was $1.030 \mathrm{~g}$, whereas after extraction in different solvents, the final dry weight was found to be $1.016 \mathrm{~g}$. The PHY, calculated from (1), is $98.14 \%$, which can be considered as high yield. It was found that for all the samples synthesized there was almost 96-99 percent yield. The films synthesized were almost transparent as shown in Figure 2.

3.2. Water Absorption Behavior of Hydrogel Films. The dynamic water uptake of hydrogel films HG1, HG2, and HG3 is shown in Figure 3. It can be observed that samples HG1 and HG2 exhibit equilibrium water uptakes of nearly 9.4 and $5.6 \mathrm{~g} / \mathrm{g}$, respectively. The observed difference in water uptake can simply be attributed to the fact that these samples contain almost 194 and 324 micromoles of cross-linker MB in their polymer networks, respectively. The hydrogel with greater amount of cross-linker produces denser cross-linked network, thus allowing less quantity of water to enter into the network. In addition, higher amount of cross produces more rigid chains due to greater number of cross-link junctions [35]. As both the samples contain same quantity of cellulose (i.e., $100 \mathrm{mg}$ ), the contribution of cellulose towards water 


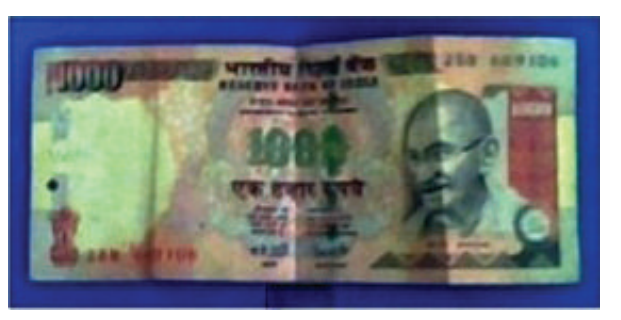

(a)

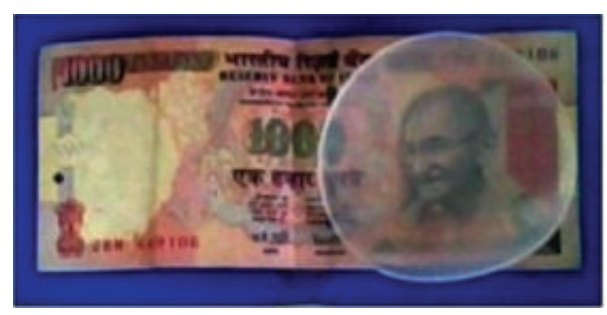

(b)

FIGURE 2: A strip of hydrogel film put on the currency note to reveal its transparency.

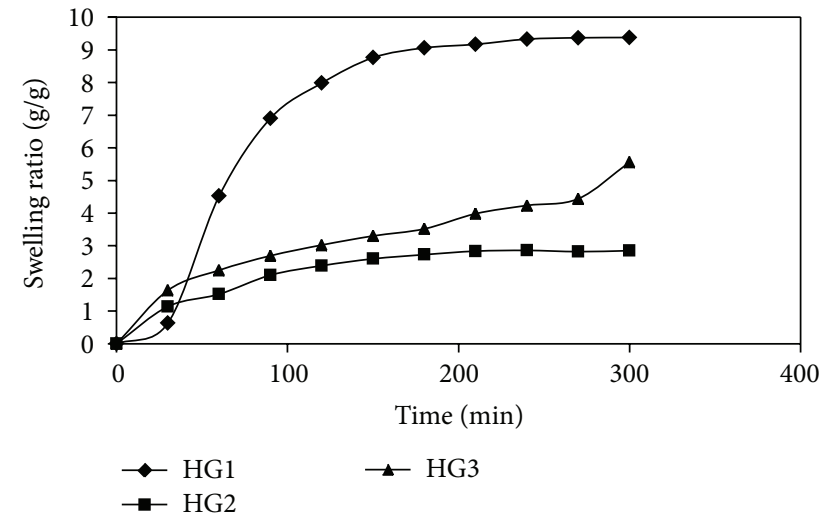

Figure 3: Dynamic uptake of water as a function of time for the hydrogel films $\mathrm{HG} 1, \mathrm{HG} 2$, and $\mathrm{HG} 3$ at $37^{\circ} \mathrm{C}$.

absorption is the same, and the amount of cross-linking agent used is the main factor to govern their water absorption behavior.

It is also noteworthy that sample HG3, which contains 324 micromoles of cross-linker MB (like sample HG2) but $60 \mathrm{mg}$ of cellulose, exhibits a total water uptake of nearly $2.85 \mathrm{~g} / \mathrm{g}$, which is the minimum of all the three samples studied. This is because the sample HG3 contains less quantity of cellulose and therefore its contribution towards total water uptake is low as compared to the sample HG2 which contains $100 \mathrm{mg}$ cellulose.

The water penetration mechanism is best described by the following logarithmic equation [36]:

$$
\ln F=\ln k+n \ln t
$$

where $F$ is the fractional water uptake at time $t, k$ is gel characteristic constant, and $n$ is swelling exponent, which indicates Fickian or non-Fickian behavior of the swelling device. The slope and intercept of linear plot, obtained between $\ln t$ and $\ln F$, enable us to evaluate $n$ and $k$, respectively. The dynamic water uptake data, displayed in Figure 3, was used to get linear plots between $\ln F$ and $\ln t$ (see Figure 4), and the swelling exponent " $n$ " and gel characteristic constant $k$ were evaluated.

The values of swelling exponent " $n$ " for the hydrogel samples HG1, HG2, and HG3 were $0.41,0.23$, and 0.47 , respectively. In addition, values of gel characteristic constants $k$ were $2.454 \times 10^{-3}, 3.706 \times 10^{-3}$, and $2.798 \times 10^{-3}$, respectively. It is to be noted that for all the samples " $n$ " values are less than

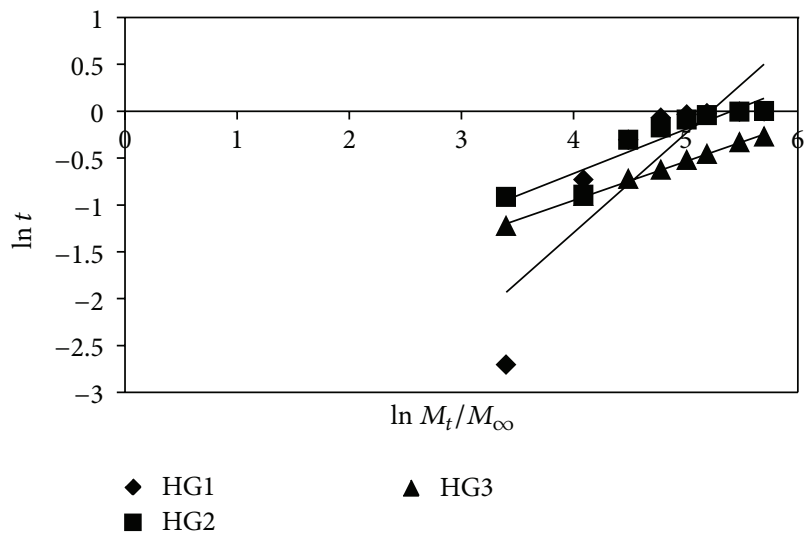

FIGURE 4: $\ln t$ versus $\ln M_{t} / M_{\infty}$ plots for the evaluation of swelling exponent $n$ and gel characteristic constant $k$ for the samples HG1, HG2, and HG3.

0.5 , thus indicating diffusion-controlled swelling mechanism. This may simply be attributed to the fact that since the cellulosic chains are entangled with poly(AAc) segments and create a densely populated entangled network, the solvent diffuses slowly into the network [37], thus indicating simple diffusion-controlled swelling mechanism.

3.3. Mechanical Properties of Hydrogel Films. The mechanical properties of wound dressing films play a significant role in establishing their suitability. The films must be able to withstand the appropriate stress when used on wounds. More importantly, the film must have significant flexibility so that it does not break during the process of exudates absorption. The flexibility of a film is usually measured in terms of percent elongation (PE). Finally, elongation at break $(E)$ is also an important parameter, which is also required to be quite fair during the application on the affected area of wound [38]. In the present study, the mechanical properties, namely, TS and PE (percent elongation), were tested for the samples HG1 and HG2, which contained 194 and 324 micromoles of crosslinker MB, respectively. The results are shown in Figure 5.

Fairly higher percent elongations of 175 and 115 for the samples HG1 and HG2 indicated a higher degree of flexibility. The fairly higher PE values indicate that these films will be beneficial in the case of wounds with higher exudates. After absorption of fluid, the films shall maintain their 


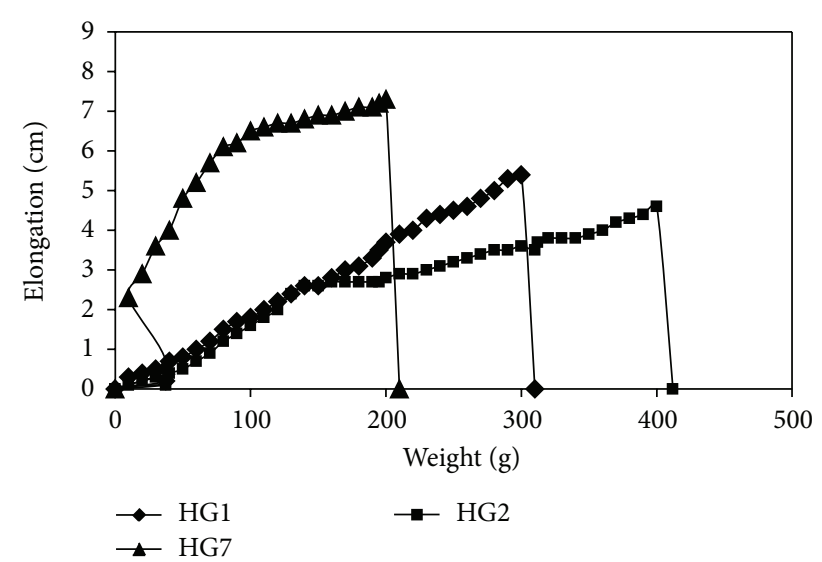

FIGURE 5: Elongation versus load profiles to determine the percent elongation at break for the samples HG1, HG2, and HG7.

structural integrity. The observed decrease in PE with $\mathrm{MB}$ content is attributable to the increased number of cross-link junction points, thus imparting more rigidity to the films. The TS values for these samples were $0.99 \mathrm{MPa}$ and $1.31 \mathrm{MPa}$, respectively. The observed increase in TS is simply indicative of increased rigidity of the films. Here it is noteworthy that the two samples contain same amount of cellulose, and so the contribution made by intermolecular $\mathrm{H}$-bonding interactions of $-\mathrm{OH}$ groups of cellulosic chains is almost the same. The values of TS, obtained with the samples HG1 and HG2, are relatively low as compared to those reported by others. For example, in a study [39], the alginate based single and bilayer hydrocolloid films possessed TS values of 20.82 and 27.22, respectively. Similarly, the wound dressing films, prepared from Haruan and fusidic acid spray, were reported to have TS values in the range of 15.09 to 28.17 [40]. The drawback of poor TS of these films may be overcome by using these films over wounds along with external supports like netted cotton strip, which may be wrapped over the film. Finally, for the sample HG7 containing $1.0 \mathrm{~mL}$ of plasticizer glycerol, the PE and TS values were found to be 248 and 1.3 $\mathrm{MPa}$, respectively. Contrary to this, sample HG1 which does not contain glycerol has PE value of 175 . This indicates that presence of glycerol enhances the percent elongation by reducing the intermolecular $\mathrm{H}$-bonding between cellulosic $-\mathrm{OH}$ groups.

From the above discussion, it is clear that hydrogel films HG1 and HG2, prepared without using glycerol, have fairly high percent elongation PE and therefore addition of glycerol is not at all necessary in the present hydrogel films. However, their TS needs to be enhanced or alternatively an external support is required for applying these films on wounds.

3.4. Moisture Permeation Analysis. Permeation of moisture through a wound dressing film is a significant parameter. In case of excessive water loss via permeation through the film, the wound may get dried and this will retard the healing process. The wound dressing film must be permeable to the moisture to an extent that neither there should be excessive

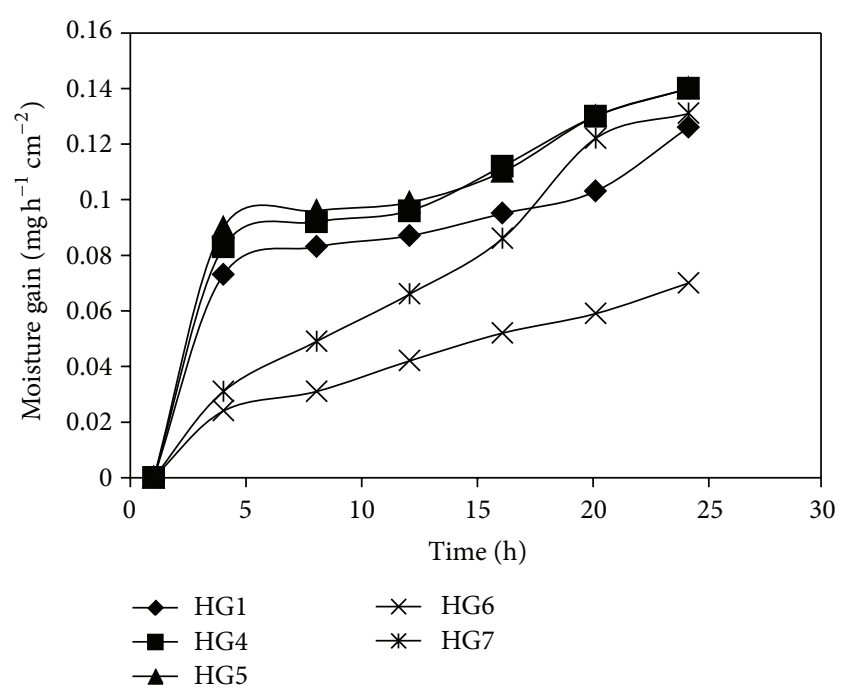

FIGURE 6: Moisture gain versus time profiles for the hydrogel films HG1, HG2, HG4, HG5, HG6, and HG7 under relative humidity atmosphere of $40 \%$.

loss of moisture to result in a dry wound, nor there should be such a low permeability which may cause leakage of exudates [41]. Therefore, the water-uptake capacity and WVTR are important factors in determining the suitability of film for a particular wound. Normally, the WVTR of the normal skin is about $0.85 \mathrm{mg} / \mathrm{cm}^{2} / \mathrm{h}$, whereas those of the injured skin can range from 1.16 to $21.41 \mathrm{mg} / \mathrm{cm}^{2} / \mathrm{h}$. The WVTR of a wound dressing film should be such that the film may prevent the wound from dehydration. Therefore, a wound dressing with a WVTR ranging from 8.33 to $10.42 \mathrm{mg} / \mathrm{cm}^{2} / \mathrm{h}$ is generally recommended [42].

The WVTR of the hydrogel film samples HG1, HG4, HG5, HG6, and HG7 were determined at the RH of 40 percent and the results of moisture gain versus time profiles are shown in Figure 6.

WVTR of films were found to be 5.91, 6.78, 7.18, 1.86, and $2.03 \mathrm{mg} / \mathrm{cm}^{2} / \mathrm{h}$, respectively. These values did not fall within the desired range of 8.33 to $10.42 \mathrm{mg} / \mathrm{cm}^{2} / \mathrm{h}$. However, samples HG1, HG4, and HG5 have WVTR values quite close to the desired range. The observed increase in WVTR of samples HG1, HG2, and HG3 can be attributed to the fact that these samples contain 100, 60, and $20 \mathrm{mg}$ of cellulose. The decrease in cellulose content results in formation of less dense network, thus permitting more moisture permeation. Moreover, decreased cellulose content lowers the H-bonding interactions among the cellulosic chains, thus reducing the number of pseudo crosslinks. It is reported that glycerol, with proper size and three hydroxyl groups, easily enters between the film forming polymers and weakens the intermolecular forces between the polymeric chains [43], thus enhancing the extensibility and moisture permeation through film. However, in the current work, the WVTR of samples HG6 and HG7 was observed to decrease, probably due to $\mathrm{H}$ bonding between -OH groups of glycerol and polar hydroxyl groups of cellulose chains. Such type of phenomenon has also been reported elsewhere $[44,45]$. 


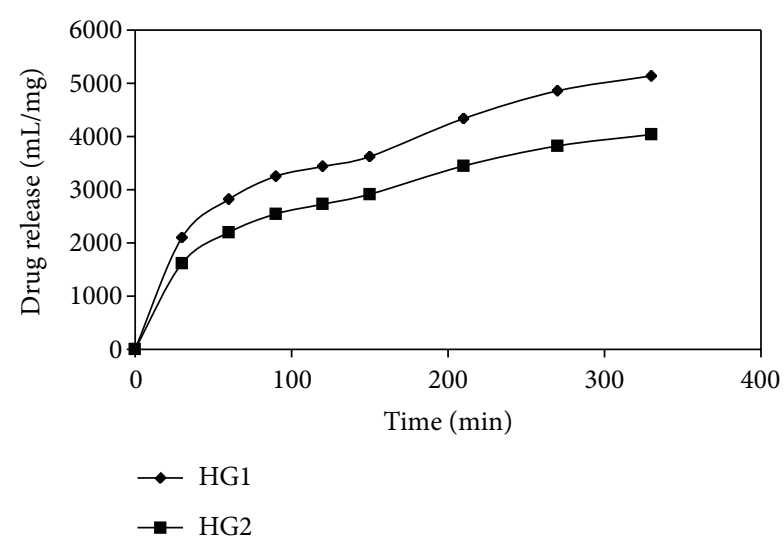

FIGURE 7: The drug release versus time profiles for the hydrogel films HG1 (5.4) and HG2 (5.4) in the physiological fluid at $37^{\circ} \mathrm{C}$.

3.5. Drug Release Study. In wound healing management studies nature of exudates is very important. The composition of wound fluid depends upon the nature of the wound. For example, Trengrove et al. [46] reported that wound fluid collected from leg ulcers contained 0.6 to $5.9 \mathrm{mM} / \mathrm{L}$ glucose and $25-51 \mathrm{~g} / \mathrm{L}$ protein. Similarly, Bonnema et al. [47] analyzed serum fluid formed after auxiliary dissection and reported that on the first operative day the drainage fluid contained blood and high concentration of creatine phosphokinase while after day 1 , it changed to lymph like fluid that contained different cells and more proteins. In this work, we carried out in vitro release study in physiological fluid (PL) as suggested by British pharmacopeias. The PF contained $142 \mathrm{mM}$ of $\mathrm{NaCl}$ and $2.5 \mathrm{mM}$ of $\mathrm{CaCl}_{2}$.

The effect of degree of cross-linking on the drug release profiles, for the samples HG1 (5.4) and HG2 (5.4), is shown in Figure 7. It is clear that sample HG1 (5.4) exhibits higher release as compared to the other sample HG2 (5.4).

This is due to the fact that as the sample HG2 (5.4) contains more quantity of cross-linker $\mathrm{MB}$, it shows less swelling and therefore slower release is observed. Since samples HG1 and HG2 show diffusion-controlled swelling ( $n=0.41$ and 0.23 , resp.), therefore diffusion-controlled model, given by Higuchi [48], was used to interpret drug release data. According to this model,

$$
Q_{t}=\frac{M_{t}}{M_{\infty}}=K_{H} t^{1 / 2},
$$

where $Q_{t}$ is the fractional release of drug at time $t$ and $K_{H}$ is the Higuchi constant. The dynamic release data of samples HG1 (5.4) and HG2 (5.4) were applied on (4) and curves were plotted between $Q_{t}$ and $t^{-1 / 2}$, as shown in Figure 8.

The plots obtained were fairly linear with an excellent regression value of 0.9723 and 0.9768 , respectively, thus supporting Higuchi diffusion-controlled release model. The values of Higuchi constants were found to be $33.1 \times 10^{-3}$ and $26.1 \times 10^{-3} \mathrm{~h}^{-1 / 2}$, respectively.

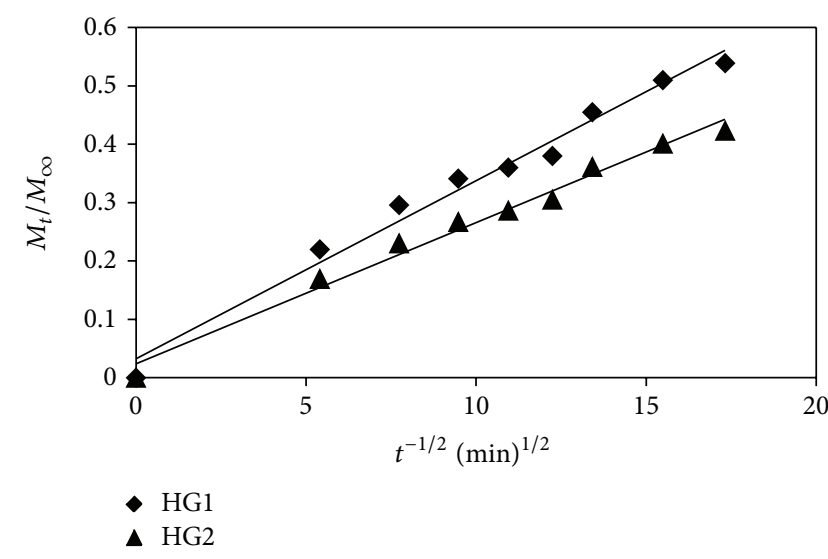

FIGURE 8: Higuchi plots for the release data observed for the samples HG1 (5.4) and HG2 (5.4).

3.6. Antibacterial Tests. The results of antibacterial experiments against model bacteria E. coli are shown in Figure 9.

It can be seen that the Petri plate, containing the plain film in Figure 9(a), shows a dense population of bacterial colonies, whereas the Petri plates, supplemented with the hydrogel films HG1 (5.4) and HG2 (5.4), show clear zones of inhibition with their respective areas $6.22 \mathrm{~cm}^{2}$ (Figure 9(c)) and $4.14 \mathrm{~cm}^{2}$ (Figure 9(b)), respectively. This may simply be attributed to the fact that more cross-linked film, that is, HG2 (5.4), shows slower release from the film and hence demonstrates poorer inhibition efficiency as compared to the other sample HG1 (5.4) which is less cross-linked and exhibits faster release as observed in release experiments.

3.7. Antifungal Tests. The results of antifungal experiments against fungus Aspergillus niger are shown in Figure 10. It is clear that the Petri plate, containing the plain film in Figure 10(a), shows growth of five colonies, whereas the Petri plates, supplemented with the hydrogel films (Figure 10(b)), HG1 (5.4), show clear zone of inhibition of fungus Aspergillus niger.

This indicates that the drug miconazole nitrate is also effective in antifungal activities too. Similarly, Najafi et al. [49] have recently reported antifungal action of a polymeric film, composed of hydroxypropyl cellulose and chitosan, loaded with miconazole nitrate. The highest loading of drug into the films was $9.6 \mathrm{mg}$.

\section{Conclusion}

From the above study it may be concluded that cellulose/poly(AAc) hydrogel films are highly flexible and have fair mechanical strength. They allow low permeation of moisture and show diffusion-controlled release of miconazole nitrate. These films show fair antibacterial and antifungal properties. Their cytotoxic studies are in progress and will be reported soon. 


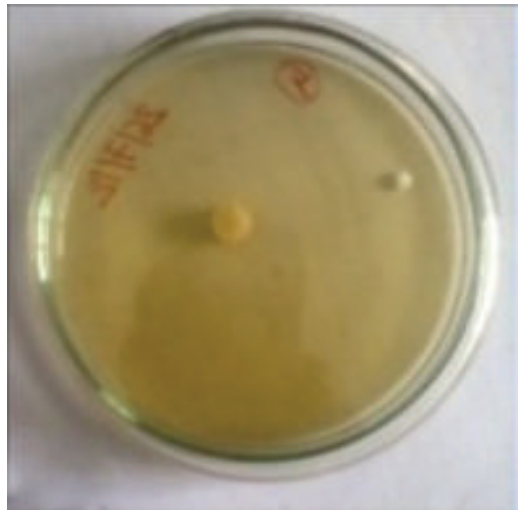

(a)

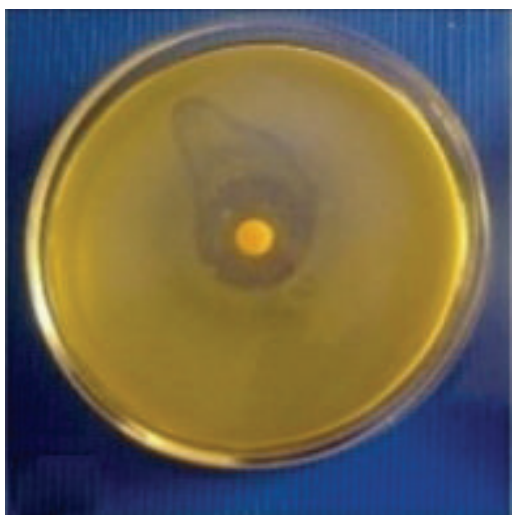

(b)

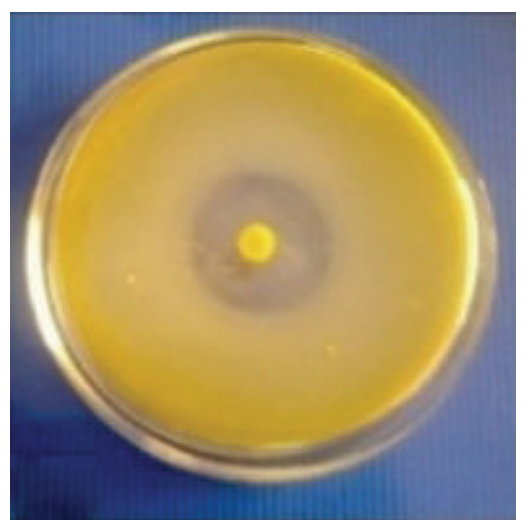

(c)

FIGURE 9: "Zones of inhibition" obtained for Petri plates supplemented with (a) plain film, (b) HG1 (5.4) film, and (c) HG2 (5.4) film.

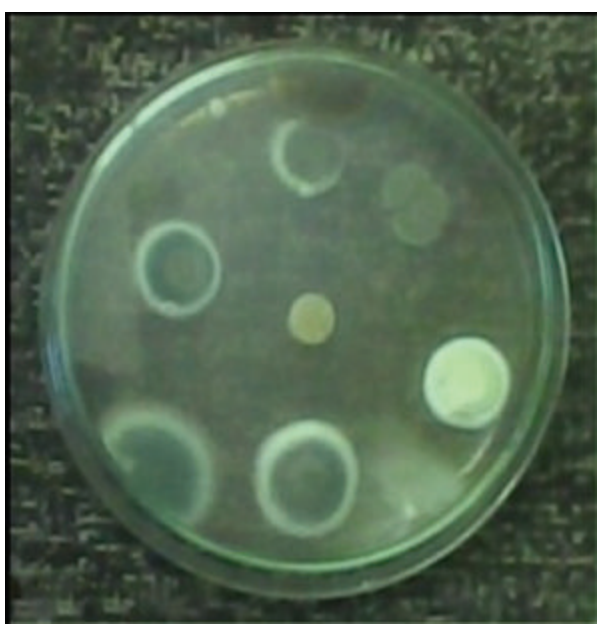

(a)

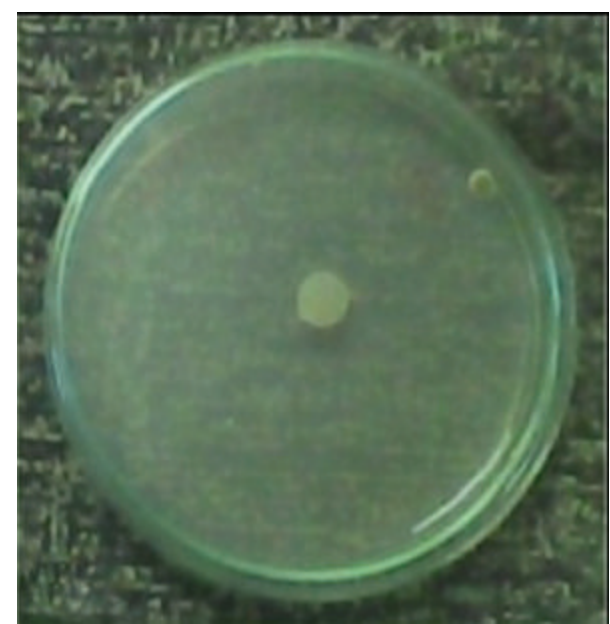

(b)

FIGURE 10: "Zones of inhibition" obtained for Petri plates supplemented with film loaded with (a) plain film and (b) miconazole nitrate.

\section{Conflict of Interests}

The authors hereby declare that there is no conflict of interests regarding the publication of this paper.

\section{References}

[1] K. Peh, T. Khan, and H. S. Ch'ng, "Mechanical, bioadhesive strength and biological evaluations of chitosan films for wound dressing," Journal of Pharmacy \& Pharmaceutical Sciences, vol. 3, no. 3, pp. 303-311, 2000.

[2] G. Majno, The Healing Hand: Man and Wound in the Ancient World, Harvard University, Cambridge, UK, 1975.

[3] S. Thomas, Wound Management and Dressing, Pharmaceutical Press, London, UK, 1990.

[4] L. G. Ovington, "Advances in wound dressings," Clinics in Dermatology, vol. 25, no. 1, pp. 33-38, 2007.

[5] T. Abdelrahman and H. Newton, "Wound dressings: principles and practice," Surgery, vol. 29, no. 10, pp. 491-495, 2011.
[6] A. J. Singer and A. B. Dagum, "Current management of acute cutaneous wounds," The New England Journal of Medicine, vol. 359, no. 10, pp. 1037-1046, 2008.

[7] M. M. G. Fouda, R. Wittke, D. Knittel, and E. Schollmeyer, "Use of chitosan/polyamine biopolymers based cotton as a model system to prepare antimicrobial wound dressing," International Journal of Diabetes Mellitus, vol. 1, no. 1, pp. 61-64, 2009.

[8] B. Steffansen and S. P. K. Herping, "Novel wound models for characterizing ibuprofen release from foam dressings," International Journal of Pharmaceutics, vol. 364, no. 1, pp. 150155, 2008.

[9] H. Xu, L. Ma, H. Shi, C. Gao, and C. Han, "Chitosan-Hyaluronic acid hybrid film as a novel wound dressing: in vitro and in vivo studies," Polymers for Advanced Technologies, vol. 18, no. 11, pp. 869-875, 2007.

[10] B. Singh and L. Pal, "Sterculia crosslinked PVA and PVApoly(AAm) hydrogel wound dressings for slow drug delivery: mechanical, mucoadhesive, biocompatible and permeability properties," Journal of the Mechanical Behavior of Biomedical Materials, vol. 9, pp. 9-21, 2012. 
[11] M. Pandima Devi, M. Sekar, M. Chamundeshwari et al., "A novel wound dressing material-Fibrin-chitosan-sodium alginate composite sheet," Bulletin of Materials Science, vol. 35, no. 7, pp. 1157-1163, 2012.

[12] H. V. Pawar, J. Tetteh, and J. S. Boateng, "Polyox and carrageenan based composite films dressings containing antimicrobial and anti-inflammatory drugs for effective wound healing," International Journal of Pharmaceutics, vol. 441, no. 1-2, pp. 181-191, 2013.

[13] S. Bielecki, A. Krystynowicz, M. Turkiewicz, and H. Kalinowska, "Bacterial cellulose," in Biopolymers: Polysaccharides I. Munster, A. Steinbuchel, Ed., vol. 5, pp. 37-90, Wiley-VCH, GmbH, Weinheim, Gremany, 2002.

[14] Y. Nishi, M. Uryu, S. Yamanaka et al., "The structure and mechanical properties of sheets prepared from bacterial cellulose-part 2: improvement of the mechanical properties of sheets and their applicability to diaphragms of electroacoustic transducers," Journal of Materials Science, vol. 25, no. 6, pp. 2997-3001, 1990.

[15] J. Shah and R. M. Brown Jr., “Towards electronic paper displays made from microbial cellulose," Applied Microbiology and Biotechnology, vol. 66, no. 4, pp. 352-355, 2005.

[16] B. R. Evans, H. M. O’Neill, V. P. Malyvanh, I. Lee, and J. Woodward, "Palladium-bacterial cellulose membranes for fuel cells," Biosensors and Bioelectronics, vol. 18, no. 7, pp. 917-923, 2003.

[17] J. D. Fontana, A. M. de Souza, C. K. Fontana et al., "Acetobacter cellulose pellicle as a temporary skin substitute," Applied Biochemistry and Biotechnology, vol. 24-25, pp. 253-264, 1990.

[18] O. M. Alvarez, M. Patel, J. Booker, and L. Markowitz, "Effectiveness of a biocellulose wound dressing for the treatment of chronic venous leg ulcers: results of a single center randomized study involving 24 patients," Wounds, vol. 16, no. 7, pp. 224-233, 2004.

[19] W. Czaja, M. Kawecki, A. Krystynowicz, K. Wysota, S. Sakiel, and P. Wroblewski, "Application of bacterial cellulose in treatment of second and third degree burns," in Proceedings of the 227th ACS National Meeting, Anaheim, Calif, USA, April 2004.

[20] M. Ul-Islam, T. Khan, W. A. Khattak, and J. K. Park, "Bacterial cellulose- MMT Nano reinforced composite films: novel wound dressing material with antibacterial properties," Cellulose, vol. 20, no. 2, pp. 589-596, 2013.

[21] I. Siró and D. Plackett, "Microfibrillated cellulose and new nanocomposite materials: a review, Cellulose, vol. 17, no. 3, pp. 459-494, 2010.

[22] W. Czaja, A. Krystynowicz, S. Bielecki, and R. M. Brown Jr., "Microbial cellulose-the natural power to heal wounds," Biomaterials, vol. 27, no. 2, pp. 145-151, 2006.

[23] J. V. Cartmell and W. R. Sturtevant, "Transparent hydrogel wound dressing," U S Patent 5106629 A, 1992.

[24] M.-R. Hwang, J. O. Kim, J. H. Lee et al., "Gentamicin-loaded wound dressing with polyvinyl alcohol/dextran hydrogel: gel characterization and in vivo healing evaluation," AAPS PharmSciTech, vol. 11, no. 3, pp. 1092-1103, 2010.

[25] M. Bajpai, S. K. Bajpai, and D. J. Goutam, "Atom transfer radical polymerization of glycidyl methacrylate (GMA) in emulsion," Journal of Macromolecular Science A Pure and Applied Chemistry, vol. 50, pp. 120-127, 2013.

[26] N. A. Pascarelli, E. Moretti, G. Terzuoli et al., "Effects of gold and silver nanoparticles in cultured human osteoarthritic chondrocytes," Journal of Applied Toxicology, vol. 33, no. 12, pp. 1506-1513, 2013.
[27] X. Q. Wang, H. E. Chang, and R. J. Francis, "Silver deposits in cutaneous burn scar tissue is a common phenomenon following application of a silver dressing," Journal of Cutaneous Pathology, vol. 36, no. 7, pp. 788-792, 2009.

[28] X. Gan, T. Liu, J. Zhong, X. Liu, and G. Li, "Effect of silver nanoparticles on the electron transfer reactivity and the catalytic activity of myoglobin," ChemBioChem, vol. 5, no. 12, pp. 1686-1691, 2004.

[29] L. Braydich-Stolle, S. Hussain, J. J. Schlager, and M.-C. Hofmann, "In vitro cytotoxicity of nanoparticles in mammalian germline stem cells," Toxicological Sciences, vol. 88, no. 2, pp. 412-419, 2005.

[30] H. Jin, C. Zha, and L. Gu, "Direct dissolution of cellulose in $\mathrm{NaOH} /$ thiourea/urea aqueous solution," Carbohydrate Research, vol. 342, no. 6, pp. 851-858, 2007.

[31] J. Zhou, C. Chang, R. Zhang, and L. Zhang, "Hydrogels prepared from unsubstituted cellulose in $\mathrm{NaOH}$ /urea aqueous solution," Macromolecular Bioscience, vol. 7, no. 6, pp. 804-809, 2007.

[32] H. Xu, L. Ma, H. Shi, C. Gao, and C. Han, "Chitosan-hyaluronic acid hybrid film as a novel wound dressing: in vitro and in vivo studies," Polymers for Advanced Technologies, vol. 18, no. 11, pp. 869-875, 2007.

[33] X. L. Shen, J. M. Wu, Y. Chen, and G. Zhao, "Antimicrobial and physical properties of sweet potato starch films incorporated with potassium sorbate or chitosan," Food Hydrocolloids, vol. 24, no. 4, pp. 285-290, 2010.

[34] "ASTM standard test method for water vapour transmission of materials," Designation E, vol. 701, pp. 93-96, 1993.

[35] S. Park, P. S. K. Murthy, S. Park, Y. M. Mohan, and W.G. Koh, "Preparation of silver nanoparticle-containing semiinterpenetrating network hydrogels composed of pluronic and poly(acrylamide) with antibacterial property," Journal of Industrial and Engineering Chemistry, vol. 17, no. 2, pp. 293-297, 2011.

[36] H. V. Chavda and C. N. Patel, "Effect of crosslinker concentration on characteristics of superporous hydrogels," International Journal of Pharmaceutical Investigation, vol. 1, no. 1, pp. 17-21, 2011.

[37] A. R. Khare and N. A. Peppas, "Swelling/deswelling of anionic copolymer gels," Biomaterials, vol. 16, no. 7, pp. 559-567, 1995.

[38] C. Özeroglu and A. Birdal, "Swelling properties of acrylamide$\mathrm{N}, \mathrm{N}^{\prime}$-methylene bis(acrylamide) hydrogels synthesized by using meso-2,3-dimercaptosuccinic acid-cerium(IV) redox couple," Express Polymer Letters, vol. 3, no. 3, pp. 168-176, 2009.

[39] V. Rattanaruengsrikul, N. Pimpha, and P. Supaphol, "Development of gelatin hydrogel pads as antibacterial wound dressings," Macromolecular Bioscience, vol. 9, no. 10, pp. 1004-1015, 2009.

[40] H. Thu, M. H. Zulfakar, and S. Ng, "Alginate based bilayer hydrocolloid films as potential slow release modern wound dressing," International Journal of Pharmaceutics, vol. 434, no. 1-2, pp. 375-383, 2012.

[41] F. Febriyenti, A. M. Noor, and S. B. B. Baie, "Mechanical properties and water vapour permeability of film from Haruan (Channa striatus) and Fusidic acid spray for wound dressing and wound healing," Pakistan Journal of Pharmaceutical Sciences, vol. 23, no. 2, pp. 155-159, 2010.

[42] B. Singh and L. Pal, "Sterculia crosslinked PVA and PVApoly(AAm) hydrogel wound dressings for slow drug delivery: mechanical, mucoadhesive, biocompatible and permeability properties," Journal of the Mechanical Behavior of Biomedical Materials, vol. 9, pp. 9-21, 2012. 
[43] Y.-B. Wu, S.-H. Yu, F.-L. Mi et al., "Preparation and characterization on mechanical and antibacterial properties of chitsoan/cellulose blends," Carbohydrate Polymers, vol. 57, no. 4, pp. 435-440, 2004.

[44] D. Jia, Y. Fang, and K. Yao, "Water vapor barrier and mechanical properties of konjac glucomannan-chitosan-soy protein isolate edible films," Food and Bioproducts Processing, vol. 87, no. 1, pp. 7-10, 2009.

[45] Q.-P. Zhong and W.-S. Xia, "Physicochemical properties of edible and preservative films from chitosan/cassava starch/gelatin blend plasticized with glycerol," Food Technology and Biotechnology, vol. 46, no. 3, pp. 262-269, 2008.

[46] N. J. Trengrove, S. R. Langton, and M. C. Stacy, "Biochemical analysis of wound fluid from nonhealing and healing chronic leg ulcers," Wound Repair and Regeneration, vol. 4, no. 2, pp. 234-239, 1996.

[47] J. Bonnema, D. A. Ligtenstein, T. Wiggers, and A. N. van Geel, "The composition of serous fluid after axillary dissection," European Journal of Surgery, vol. 165, no. 1, pp. 9-13, 1999.

[48] T. Higuchi, "Mechanism of sustained-action medication. Theoretical analysis of rate of release of solid drugs dispersed in solid matrices," Journal of Pharmaceutical Sciences, vol. 52, no. 12, pp. 1145-1149, 1963.

[49] R. B. Najafi, Z. Maghrouri, and M. Peikanpour, "Preparation and pharmaceutical evaluation of miconazole nitrate mucoadhesive films for vaginal candidiasis," Journal of Isfahan Medical School, vol. 30, no. 216, pp. 2103-2112, 2013. 

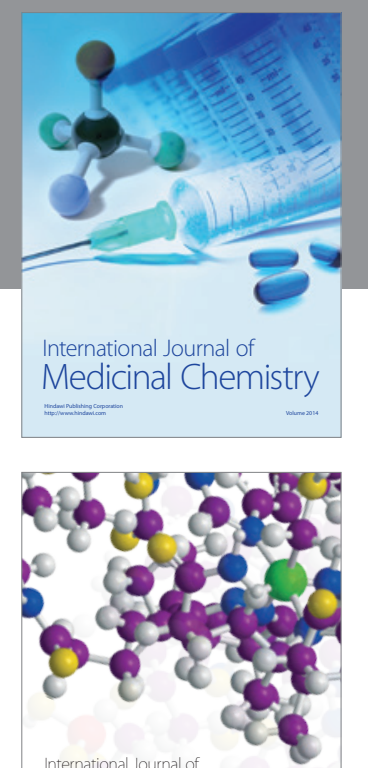

\section{Carbohydrate} Chemistry

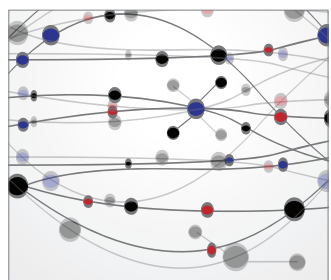

The Scientific World Journal
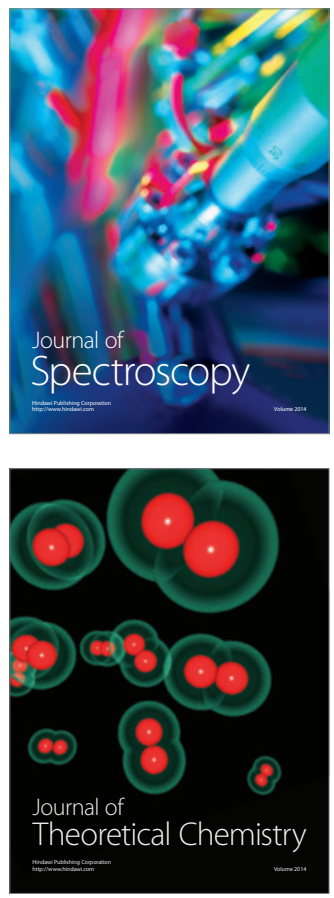
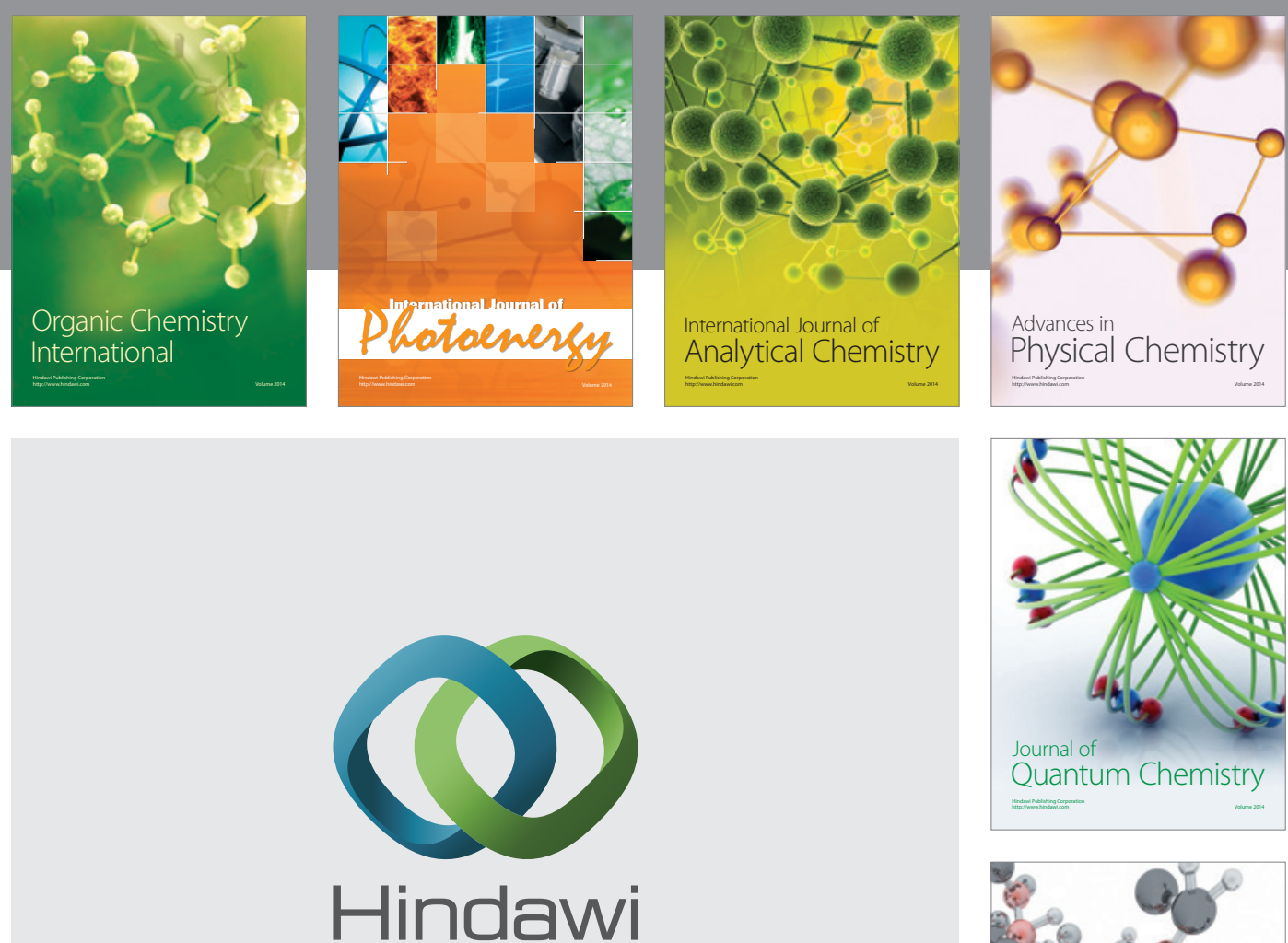

Submit your manuscripts at

http://www.hindawi.com

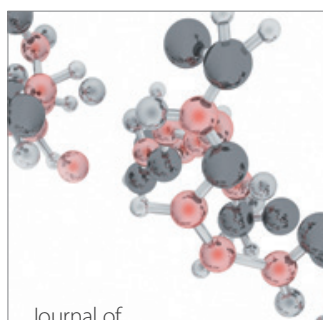

Analytical Methods

in Chemistry

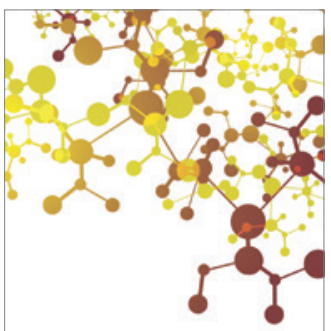

Journal of

Applied Chemistry

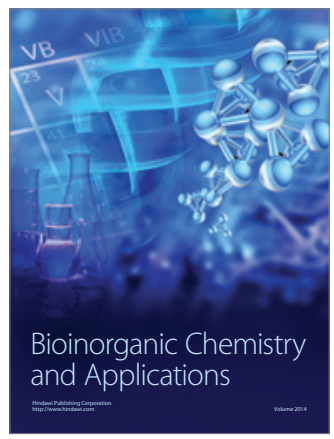

Inorganic Chemistry
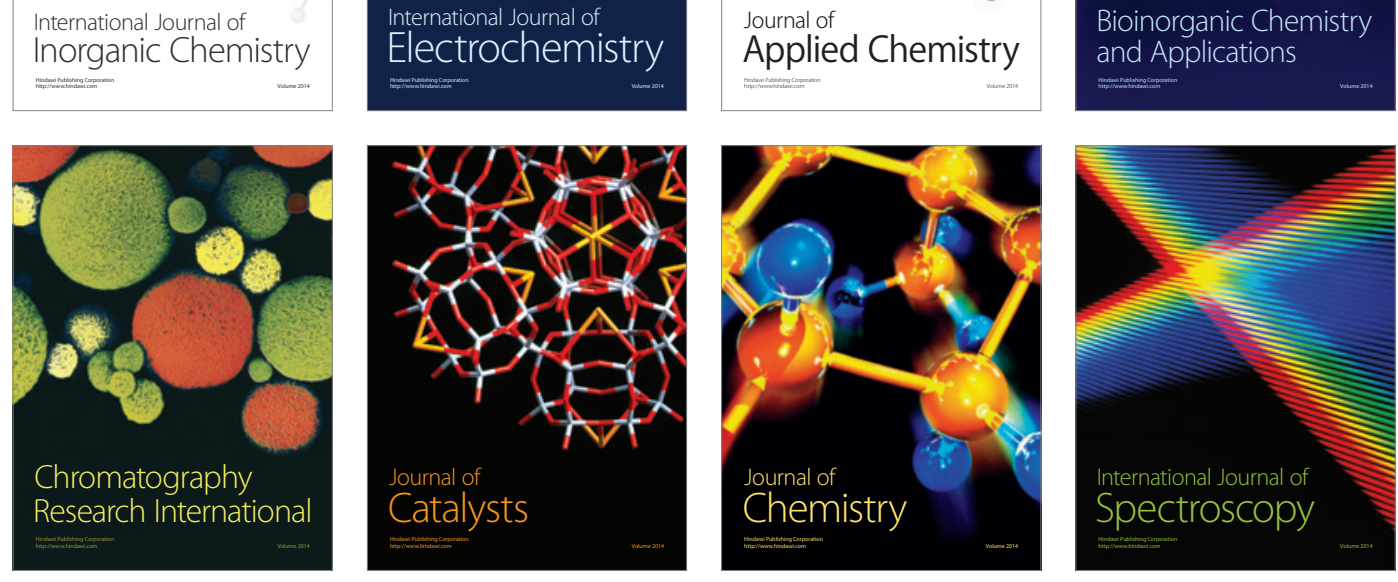